\title{
ANNOUNCEMENT
}

\section{Scientific meeting}

\section{INTERNATIONAL GRAVITY WORKSHOP}

\author{
Paris, 26-28 October 1981
}

An international workshop on precise gravity measurements will be held at the Institut de Physique du Globe, Université de Paris, in connection with an intercomparison of absolute gravimeters.

The principal topics of the meeting will be

- absolute and relative high-precision gravimetry and associated problems :

- data reduction; systems of reference; data combination ;

- detection and elimination of systematic and periodical errors as well as of other instrumental effects :

- physical and geophysical data modeling ;

- discussion of the program of the international D - meter campaign to be held in West-Germany in April 1982.

The workshop is organized by Special Study Groups 3.37 and 3.40 .

Interested colleagues should immediately contact the convenor:

Prof. E. Groten

Institute of Physical Geodesy

Petersenstrasse 13

Technical University Darmstadt

6100 Darmstadt, Federal Republic of Germany. 